\title{
A Meta-Analysis on the Effects of Hydroxychloroquine on COVID-19
}

Nowair Hussain ${ }^{1}$, Emily Chung ${ }^{1}$, Jonathan J. Heyl ${ }^{1}$, Bisma Hussain ${ }^{1}$, Michael C. Oh ${ }^{1}$, Candis Pinon ${ }^{2}$, Soumya Boral ${ }^{3}$, David Chun ${ }^{4}$, Benson Babu ${ }^{5}$

1. Medicine, St. John's Episcopal Hospital, New York, USA 2. Medicine, Mount Sinai Hospital, New York, USA 3. Medicine, Presidency University, Kolkata, IND 4. Medicine, Northwell Health, New York, USA 5. Hospital Medicine, Northwell Health, New York, USA

Corresponding author: Benson Babu, bensonbabumd@gmail.com

\section{Abstract \\ Introduction}

Since December 2019, severe acute respiratory syndrome coronavirus 2 (SARS-CoV-2) has rapidly spread throughout the world with a large medical and economic impact. On March 12, 2020, the World Health Organization (WHO) classified SARS-CoV-2 as a pandemic. As a result of this worldwide public health crisis, politicians, elected officials, and healthcare professionals emergently began trialing hydroxychloroquine (HCQ) in efforts to treat and prevent the transmission of the virus. This meta-analysis was performed to assess the effects of HCQ on patients with COVID-19.

\section{Methods}

This meta-analysis adheres to the Preferred Reporting Items for Systematic Reviews and Meta-Analyses (PRIMA) guidelines. Selected articles published between December 2019 and July 2020 were found utilizing the following search engines: PubMed, Google Scholar, Cochrane Library, DisasterLit, Clinicaltrials.gov, Medrxiv, and Embase. Two independent physician reviewers screened eligible articles that met the inclusion and exclusion criteria of the analysis. The outcome measures analyzed were mortality rate, rate of disease progression/improvement, rate of disease severity, and adverse effects of treatment. Six out of 14 studies that met the study's eligibility criteria were selected and further analyzed, with a total of 381 participants $(n=381)$.

\section{Conclusion}

From the studies analyzed, it was found that groups treated with HCQ had an overall mortality rate that was 2.5 times greater than that of the control group. HCQ treated patients had higher rates of adverse clinical outcomes and side effects compared with the control populations. Lastly, there was a 1.2 times higher rate of improvement in the group of HCQ treated patients with mild to moderate symptoms as compared to the control group.

Received 08/03/2020

Review began $08 / 03 / 2020$

Review ended 08/13/2020

Published 08/24/2020

(c) Copyright 2020

Hussain et al. This is an open access article distributed under the terms of the Creative Commons Attribution License CC-BY 4.0., which permits unrestricted use, distribution, and reproduction in any medium, provided the original author and source are credited.

Categories: Internal Medicine, Infectious Disease, Public Health

Keywords: hydroxychloroquine, chloroquine, azithromycin, covid-19, coronavirus, sars-cov-2

\section{Introduction}

Coronavirus disease (COVID-19) originated in Wuhan, Hubei Province of China on December 15, 2019 [14]. The rapid spread of the virus led the World Health Organization (WHO) to announce COVID-19 as a pandemic on March 12, 2020 [5]. The spread of SARS-CoV-2 resulted in an enormous public health crisis with high patient mortality and significant economic consequences [1,6]. Furthermore, COVID-19 is a complex, multifaceted, multi-system disease process that spares no one [7].

The COVID-19 acute respiratory distress syndrome consists of a period of cytokine storm, which is noted particularly in the later stages of advanced severe respiratory failure [8]. COVID-19 patients have increased levels of plasma pro-inflammatory cytokines and chemokines [9-10]. These cytokines and chemokines are IL1b, IL1RA, IL7, IL8, IL9, IL10, basic FGF2, GCSF, GMCSF, IFNg, IP10, MCP1, MIP1a, MIP1b, PDGFB, TNFa, and VEGFA [9-10]. High patient mortality is caused by the disarray of these host cytokines, causing damage to the lungs and leading to multi-system organ failure [10-11].

The SARS-CoV-2 virus has an affinity for the ciliated cells of the respiratory conducting airway, with increased viral replication as it progresses further along the respiratory tract and gastrointestinal mucosa [12]. The SARS CoV-2 infection occurs in three distinct stages: an asymptomatic stage, an upper airway stage, and, finally, the conducting airway response stage, which leads to the classically seen ground-glass infiltrates on chest X-ray and clinical hypoxia with progression to acute respiratory distress syndrome (ARDS) and multi-system dysfunction [13]. In stage 1, the virus binds to the angiotensin-converting enzyme 
2 (ACE2) receptor, a transmembrane protease, serine 2 (TMPRSS2). TMPRSS2 is ubiquitous in the human body; it is found in the nasal cavity and lung and is also expressed throughout the intestine and prostate [14]. ACE2 receptors can also be found in the heart, esophagus, kidneys, stomach, bladder, and ileum [12,14]. As SARS-CoV-2 progresses down the respiratory tract, the virus begins to activate a more potent immune response and certain patients may manifest clinically with respiratory failure and ARDS.

Most patients will have a mild disease, with the disease restricted to the upper respiratory tract [13]. About one out of five SAR-CoV-2 infected patients will progress to more severe respiratory disease and further to ARDS [13]. The proposed mechanism is the destruction of type II pneumocytes once the virus reaches the alveoli [12]. The virus would then begin the replication process within these cells and the cell would undergo apoptosis, releasing viral particles. This cellular apoptosis results in diffuse alveolar damage with the formation of hyaline membranes, which decrease gas exchange and lead to clinical hypoxia. Furthermore, the healing of the affected areas may worsen the patient's condition through more severe parenchymal scarring and fibrosis. Because the cytokines mentioned above have binding sites within the lungs, they may serve as therapeutic targets.

4-Aminoquinolones such as hydroxychloroquine (HCQ) and chloroquine have gained a lot of steam in the medical field and media for their possible efficacy against COVID-19. HCQ has immunomodulatory properties and was originally developed as an antimalarial drug with further applications in patients with rheumatoid arthritis and systemic lupus erythematosus [15]. In vitro studies of HCQ have additionally shown antiviral properties; it supposedly prevents COVID-19 related ARDS [8,15-16]. The treatment of COVID-19 positive patients with HCQ has been met with controversy, as there have been no large multicenter randomized control trials to support its use. Up to this point, there is a lack of statistically significant reduction in morbidity or mortality in COVID-19 patients who have undergone HCQ trials.

The treatment of COVID-19 with a combination of hydroxychloroquine and azithromycin was first proposed in a controversial, small non-randomized trial from the South of France that concluded that the drug combination was effective for the treatment of COVID-19 [17]. Criticism was brought on immediately when it was presented for peer review due to many methodological flaws, with the biggest being the lack of a randomized control group [17]. This led to various expert researchers criticizing the efficacy of hydroxychloroquine, with the majority concluding no statistically significant difference between treatment groups.

The emergent approval of HCQ at the height of the COVID-19 pandemic was considered controversial but necessary given the overwhelming lack of effective treatment options at that time. The controversy was limited not only to the unknown efficacy and side-effect profile of HCQ but also to the limited supply of the drug [18].

\section{Materials And Methods}

This systematic review and meta-analysis adheres to the Preferred Reporting Items for Systematic Reviews and Meta-Analyses (PRISMA) guidelines (Figure 1) [2]. The search terms used were hydroxychloroquine, chloroquine, azithromycin, COVID-19, coronavirus, and SARS-CoV-2. Using these terms, the systematic search strategies used were boolean and fuzzy logic, truncated terms, and wild cards. Selected articles published between December 2019 and July 2020 were found utilizing the following search engines: PubMed, Google Scholar, Cochrane Library, DisasterLit, Clinicaltrials.gov, Medrxiv, and Embase. Two independent physician reviewers screened eligible articles that met the analysis' inclusion and exclusion criteria. The inclusion criteria were (1) age range 12-65, (2) prospective control trial, and (3) use of hydroxychloroquine, chloroquine, lopinavir-ritonavir, or azithromycin. The exclusion criteria were (1) presence of a co-morbid medical condition, i.e., advanced heart, liver, or renal disease or diabetes mellitus, (2) treatment with remdesivir, convalescent plasma, corticosteroids, vaccines, IL-6 inhibitors, T-cell therapy, $\alpha$-ketoamide inhibitors, resiniferatoxin, teicoplanin, favipiravir, extracorporeal therapy, or HCQ prophylaxis. 


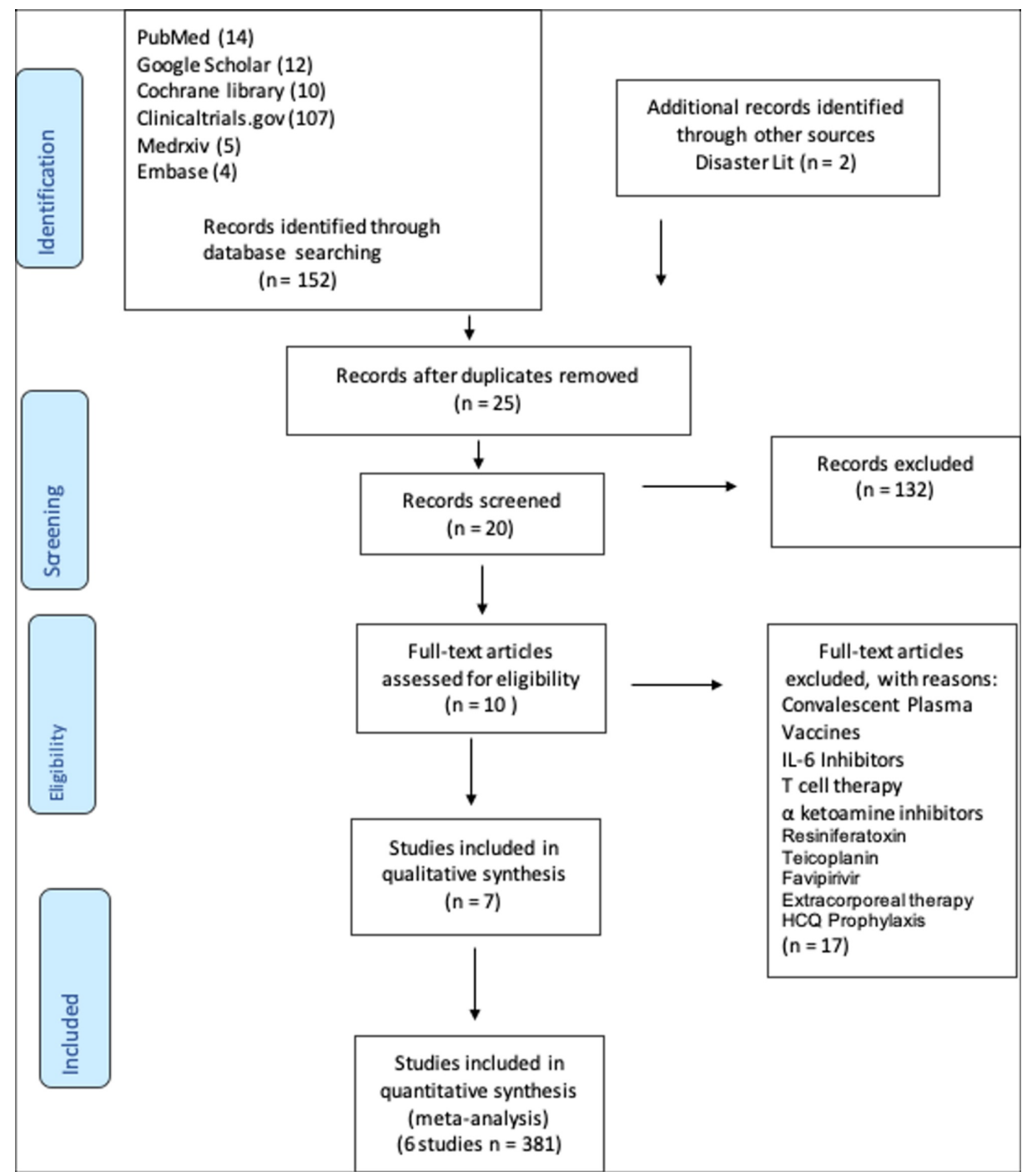

FIGURE 1: PRISMA flow diagram

PRISMA: Preferred Reporting Items for Systematic Reviews and Meta-Analyses

The outcome measures analyzed were HCQ's effect on COVID-19 mortality rate, rate of disease progression/rate of improvement, rate of disease severity, and adverse effects of treatment. Six out of 14 studies that met the study's eligibility criteria were selected and further analyzed, with a total of 381 participants $(\mathrm{n}=381)$.

Data collected from six different studies looked at the effects of HCQ on patients with clinically proven COVID-19 infection. These six studies have been labeled S1, S2, S3, S4, S5, and S6 for better data visualization. Each study varies in sample sizes and the distribution of treatment and control groups. The defined outcomes studied in this meta-analysis are:

1) The mortality rate of patients after applying HCQ on patients with COVID-19

2) The rate of progression/improvement of COVID-19 disease

3) The rate of COVID-19 disease severity, for example, after applying the HCQ treatment, the rate of which patients went on to develop severe conditions such as acute hypoxic respiratory failure and adult respiratory distress syndrome.

The random-effects model was used on the assumption that the study effect estimates show more variance when drawn from a single population [19]. Therefore, this follows the so-called assumption of exchangeability [19]. This means that in a random-effects model fit, not only do assumptions of the effects of individual studies deviate from the true intervention effect of all studies due to sampling error but that there is another source of variance introduced by the fact that the studies do not stem from one single 


\section{Cureus}

population [19]. The studies are sampled from a "universe" of populations [19]. In this study, the random effect model is a suitable choice because it is a risky assumption to state all the studies along with their respective effect sizes stem from a single homogeneous population.

\section{Results}

\section{Section A: meta-analysis on mortality rates}

Among the six studies considered for meta-analysis, information on mortality rates was available in two of them, details of which are provided below (Tables 1-3).

\begin{tabular}{|c|c|c|c|c|c|c|}
\hline Name & Author & $\begin{array}{l}\text { Sample } \\
\text { Size }\end{array}$ & $\begin{array}{l}\text { num_ } \\
\text { control }\end{array}$ & $\begin{array}{l}\text { num } \\
\text { treatment }\end{array}$ & $\begin{array}{l}\text { mortality } \\
\text { control }\end{array}$ & $\begin{array}{l}\text { mortality } \\
\text { treatment }\end{array}$ \\
\hline $\begin{array}{l}\text { A pilot study of hydroxychloroquine in the treatment of } \\
\text { patients with common coronavirus disease-19 (COVID-19) }\end{array}$ & $\begin{array}{l}\text { Chen J, et } \\
\text { al. [20] }\end{array}$ & 30 & 15 & 15 & 0 & 0 \\
\hline $\begin{array}{l}\text { Effect of high VS low doses of chloroquine diphosphate as } \\
\text { adjunctive therapy for patients hospitalized with severe acute } \\
\text { respiratory syndrome coronavirus } 2 \text { (SARS-CoV-2) infection: a } \\
\text { randomized clinical trial. }\end{array}$ & $\begin{array}{l}\text { Borba, } \\
\text { Mayla } \\
\text { Gabriela } \\
\text { Silva, et al. } \\
\text { [21] }\end{array}$ & 81 & 40 & 41 & 6 & 16 \\
\hline
\end{tabular}

\section{TABLE 1: Studies used in the meta-analysis of mortality rate}

\begin{tabular}{|c|c|c|c|c|c|}
\hline Estimate & Standard error & $Z$ value & P-value & Lower bound & Upper bound \\
\hline 0.9324 & 0.4409 & 2.1148 & 0.0344 & 0.0683 & 1.7965 \\
\hline
\end{tabular}

TABLE 2: Fitted random effect model

\begin{tabular}{|c|c|c|c|}
\hline Measure & Estimate & Lower Bound & Upper Bound \\
\hline $\operatorname{tau}^{\wedge} 2$ & 0 & 0 & $>100.0000$ \\
\hline tau & 0 & 0 & $>10.0000$ \\
\hline I^2(\%) & 0 & 0 & $>97.9720$ \\
\hline $\mathrm{H}^{\wedge} 2$ & 1 & 1 & $>49.3097$ \\
\hline
\end{tabular}

TABLE 3: Heterogeneity measure

Here, the estimated average log relative risk is equal to ${ }^{\wedge} \mu=0.9324$ ( $95 \%$ CI: 0.0683 to 1.7965 ). For easier interpretation, it may be useful to transform these values back to the relative risk scale through exponentiation (i.e., $\exp \left({ }^{\wedge} \mu\right)=2.54$ with $95 \%$ CI: 1.07 to 6.03 ). The interpretation of these results, therefore, suggests that the risk of mortality in HCQ treated individuals is on average 2.5 times greater than in nonHCQ individuals. The null hypothesis H0: $\mu=0$ can be clearly rejected $(\mathrm{p}<0.05)$.

These studies are perfectly homogeneous as tau^2 is 0 (equivalently, $\mathrm{H}^{\wedge} 2$ is 1 ). See Figures $2-3$ for more information. 


\section{Cureus}

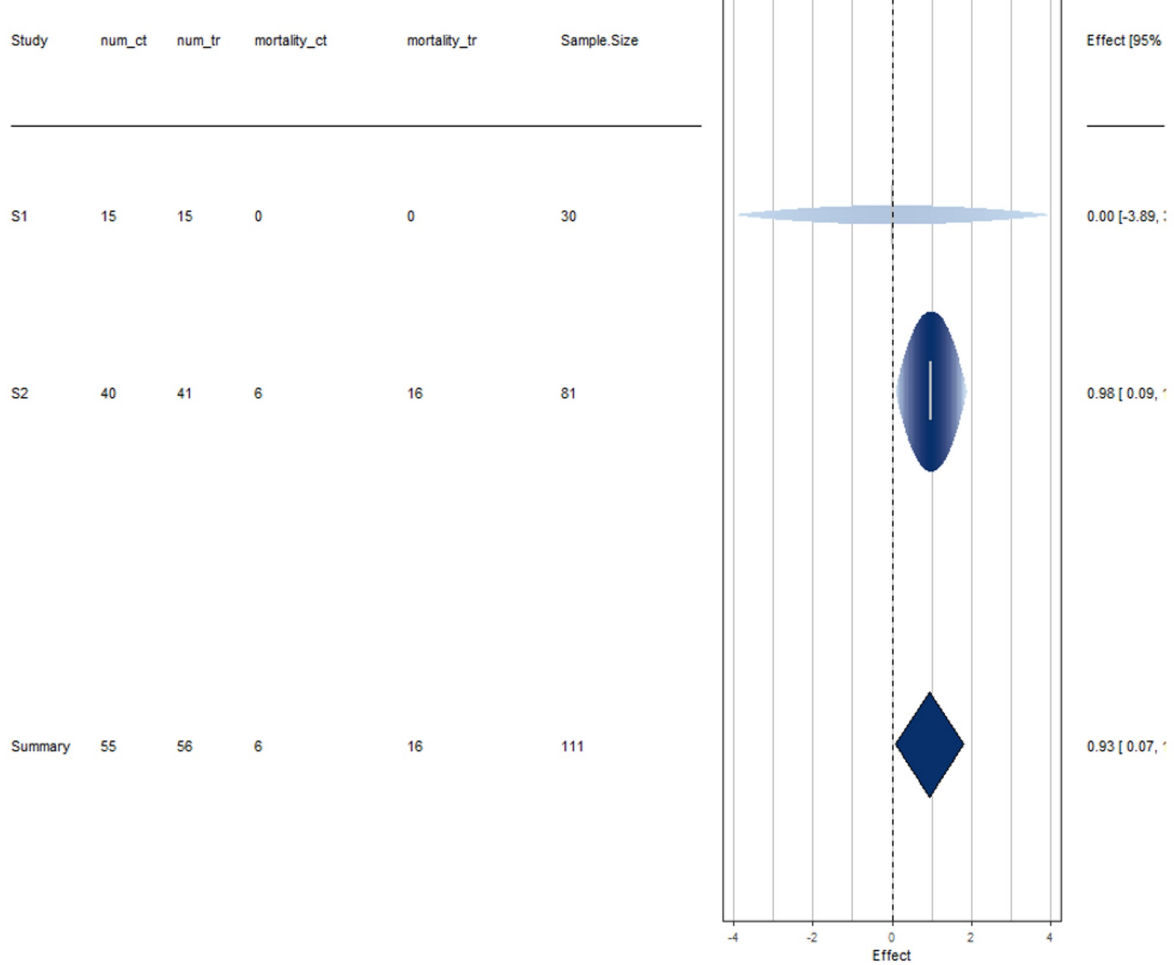

FIGURE 2: Disease mortality forest plot

Interpretation

Study 1 has more uncertainty in its results as evident due to the wide spread of the horizontal line. Studies 1 and 2 both do not cross the effect line at 0 , indicating that they are not in agreement with the mortality rate of HCQ treated COVID-19 positive patients. 


\section{Cureus}

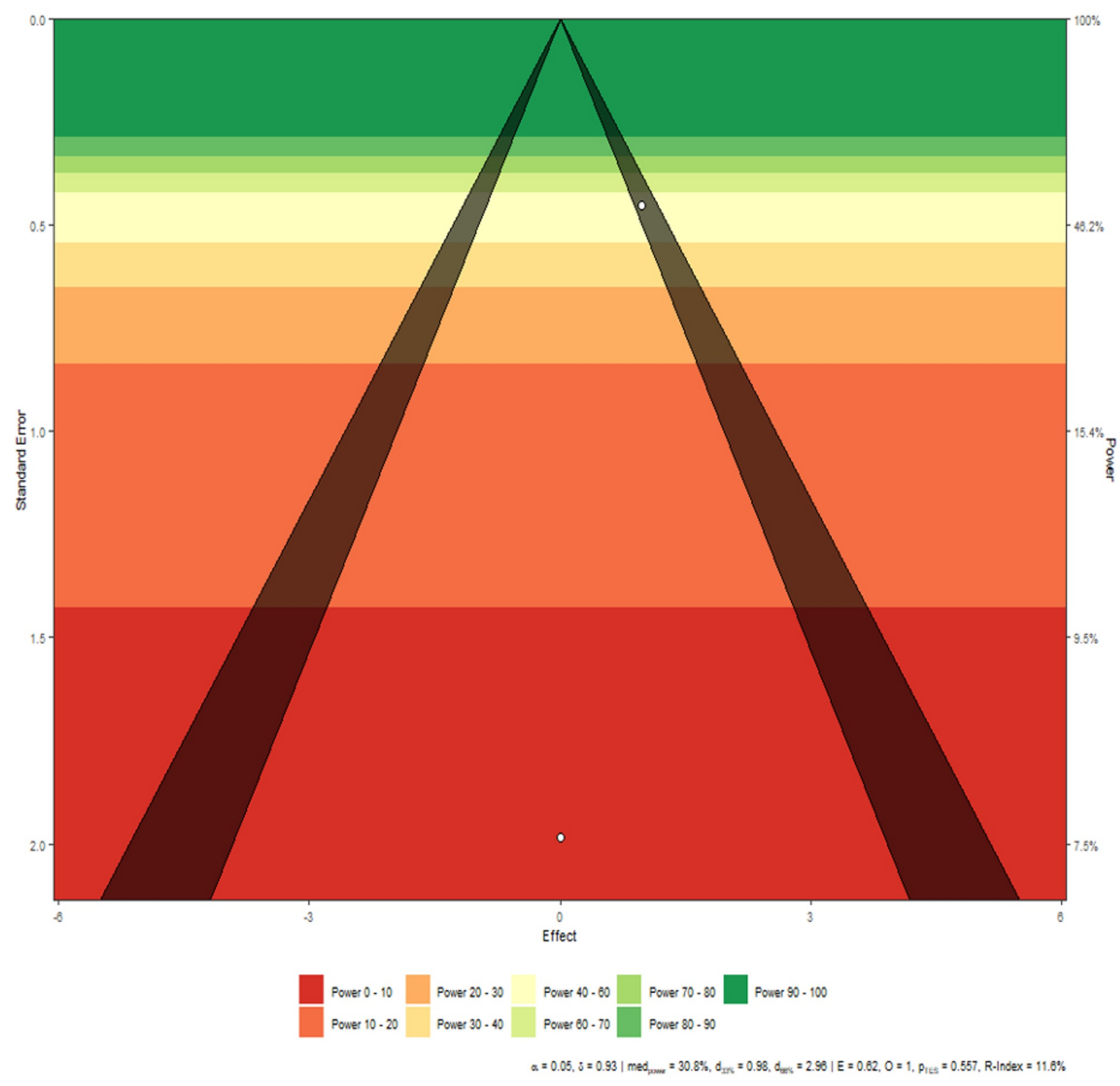

\section{FIGURE 3: Disease mortality funnel plot}

Interpretation

There is a marginal asymmetry between the studies, however, as the number of studies is small, this result can be attributed purely to chance rather than any actual publication bias.

\section{Section B: meta-analysis on progression/improvement rates}

Among the six studies considered for meta-analysis, information on disease progression rates are available in four of them, details of which are provided below (Tables 4-6).

\section{Name}

A pilot study of hydroxychloroquine in the treatment of patients with common coronavirus disease-19 (COVID 19)

Efficacy of hydroxychloroquine in patients with COVID-19 results of a randomized clinical trial

Treating COVID-19 with Chloroquine

Hydroxychloroquine and azithromycin as a treatment of COVID-19 results of an open-label non- randomized clinical trial

\begin{tabular}{|c|c|c|c|c|c|}
\hline Author & $\begin{array}{l}\text { Sample } \\
\text { Size }\end{array}$ & $\begin{array}{l}\text { num_ } \\
\text { control }\end{array}$ & $\begin{array}{l}\text { num_ } \\
\text { treatment }\end{array}$ & $\begin{array}{l}\text { progression } \\
\text { control }\end{array}$ & $\begin{array}{l}\text { progression } \\
\text { treatment }\end{array}$ \\
\hline $\begin{array}{l}\text { Chen J, } \\
\text { et al. [20] }\end{array}$ & 30 & 15 & 15 & 7 & 5 \\
\hline $\begin{array}{l}\text { Chen et } \\
\text { al. [22] }\end{array}$ & 62 & 31 & 31 & 17 & 25 \\
\hline $\begin{array}{l}\text { Huang, } \\
\text { et al. [23] }\end{array}$ & 22 & 12 & 10 & 11 & 10 \\
\hline $\begin{array}{l}\text { Gautret, } \\
\text { et al. [17] }\end{array}$ & 36 & 16 & 20 & 0 & 20 \\
\hline
\end{tabular}

TABLE 4: Studies used in meta-analysis of improvement/progression rate 


\section{Cureus}

\begin{tabular}{|c|c|c|c|c|c|}
\hline Estimate & Standard error & $Z$ value & P-value & Lower bound & Upper bound \\
\hline 0.1839 & 0.2302 & 0.7987 & 0.4245 & -0.2673 & 0.6351 \\
\hline
\end{tabular}

TABLE 5: Fitted Random Effect Model

\begin{tabular}{|c|c|c|c|}
\hline Measure & Estimate & Lower bound & Upper bound \\
\hline $\tan ^{\wedge} 2$ & 0.0495 & 0 & 48.0704 \\
\hline tau & 0.2224 & 0 & 6.9333 \\
\hline |^2(\%) & 22.4095 & 0 & 99.6449 \\
\hline $\mathrm{H}^{\wedge} 2$ & 1.2888 & 1 & 281.598 \\
\hline
\end{tabular}

\section{TABLE 6: Heterogeneity measure}

Here, the estimated average log relative risk is equal to ${ }^{\wedge} \mu=0.1839$ (95\% CI: -0.2673 to 0.6351 ) [4]. For easier interpretation, these values were transformed back to the relative risk scale through exponentiation (i.e., $\exp \left({ }^{\wedge} \mu\right)=1.2019$ with $95 \%$ CI: 0.77 to 1.89 ). The interpretation of the results suggests that the disease progression rate in HCQ treated individuals is on average 1.2 times as large as the non-HCQ individuals. The null hypothesis $\mathrm{H} 0: \mu=0$ cannot be rejected $(\mathrm{p}>0.05$ ).

These studies are a bit heterogeneous, though by a very small amount. See Figures 4-5 for more information.

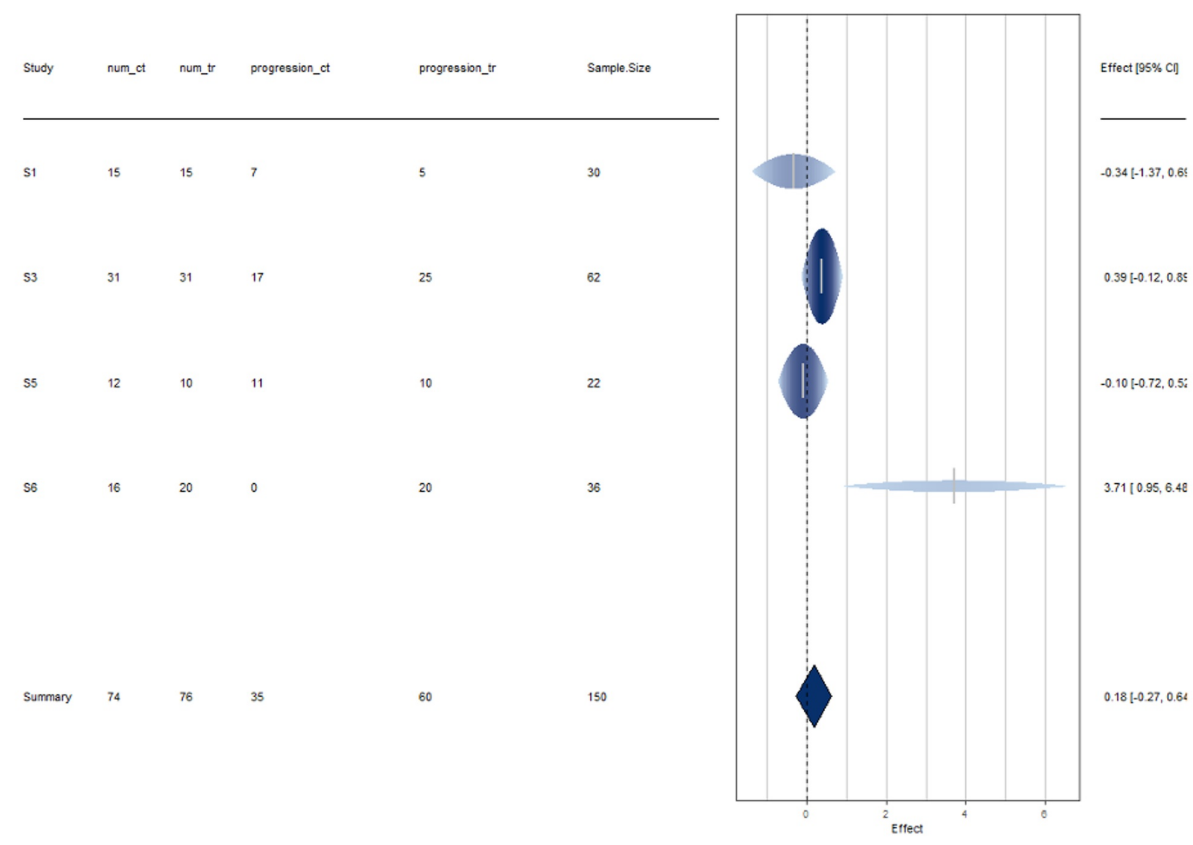

FIGURE 4: Disease progression forest plot

Interpretation

Study 6 has more uncertainty in its results as evident by the width of the horizontal line [19]. All studies, except Study 6, are in agreement with the results of a disease progression rate of HCQ treatment in patients with COVID [19]. 


\section{Cureus}

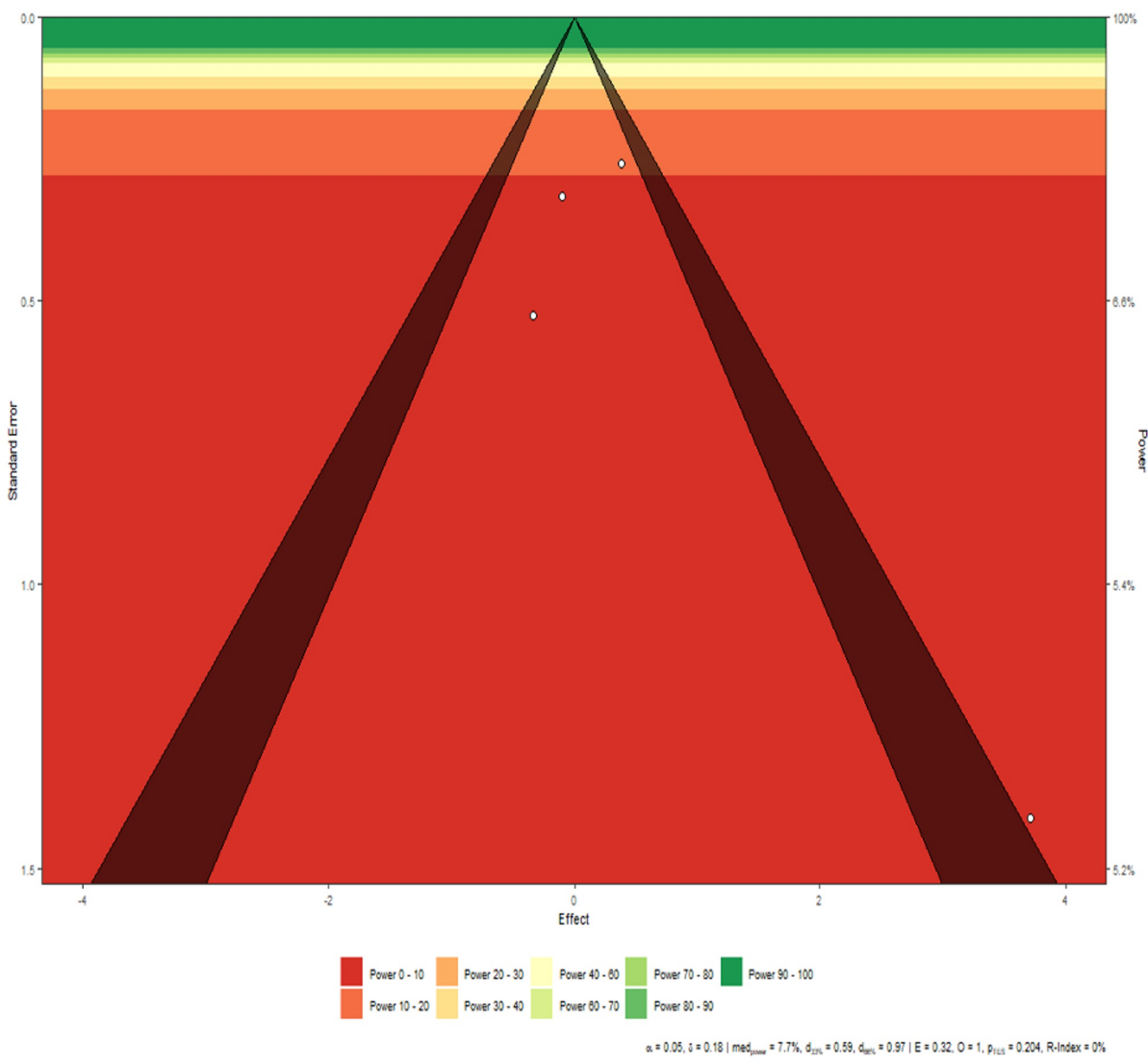

\section{FIGURE 5: Disease progression funnel plot}

Interpretation

The studies are symmetric except Study 6, which falls outside the triangle. This is in line with the conclusion drawn from the funnel plot. However, as evidenced by the funnel plot, Study 6 has very low power and thus

its effect can be ignored.

\section{Section C: meta-analysis on severity rates}

Among the six studies considered, information on disease severity rates are available in four, the details of which are provided below (Tables 7-9).

A pilot study of hydroxychloroquine in the treatment of patients with common coronavirus disease 19 (COVID19)

Hydroxychloroquine in patients with COVID-19: an open- Tang, et al. label, randomized, controlled trial

Treating COVID-19 with chloroquine

Hydroxychloroquine: small effects in mild disease

Chen J, et al.

[20]

[24]

[23]

\section{Author}

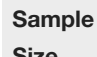

Size

num

control treatmer

severe_or

adverse_control

Huang, et al.

Levantovsky,

et al. [25]
30

15

15

0

1

150

80

70

7

21

62

2

12

$31 \quad 31$

TABLE 7: Studies used in meta-analysis of severity rate 


\section{Cureus}

\begin{tabular}{|c|c|c|c|c|c|}
\hline Estimate & Standard error & $Z$ value & P-value & Lower bound & Upper bound \\
\hline-0.3644 & 0.9996 & -0.3645 & 0.7155 & -2.3236 & 1.5949 \\
\hline
\end{tabular}

TABLE 8: Fitted random effect model

\begin{tabular}{|c|c|c|c|}
\hline Measure & Estimate & Lower bound & Upper bound \\
\hline $\tan \wedge 2$ & 2.4987 & 0 & 51.7919 \\
\hline tau & 1.5807 & 0 & 7.1967 \\
\hline$\left.\right|^{\wedge} 2(\%)$ & 65.7314 & 0 & 97.5465 \\
\hline $\mathrm{H}^{\wedge} 2$ & 2.9181 & 1 & 40.7582 \\
\hline
\end{tabular}

\section{TABLE 9: Heterogeneity measure}

Here, the estimated average log relative risk is equal to ${ }^{\wedge} \mu=-0.3644$ (95\% CI: -2.3236 to 1.5949$)$ [19]. For easier interpretation, these values are transformed back to the relative risk scale through exponentiation (i.e., $\exp (\hat{\mu} \mu)=0.6946$ with $95 \% \mathrm{CI}: 0.10$ to 4.92 ). The interpretation of these results suggests that the disease severity rate in HCQ treated individuals is on average 0.69 that of the non-HCQ individuals. The null hypothesis $\mathrm{H} 0$ : $\mu=0$ can be rejected $(\mathrm{p}<0.05)$.

These studies exhibit heterogeneity by a moderate amount. See Figures 6-7 for more information.

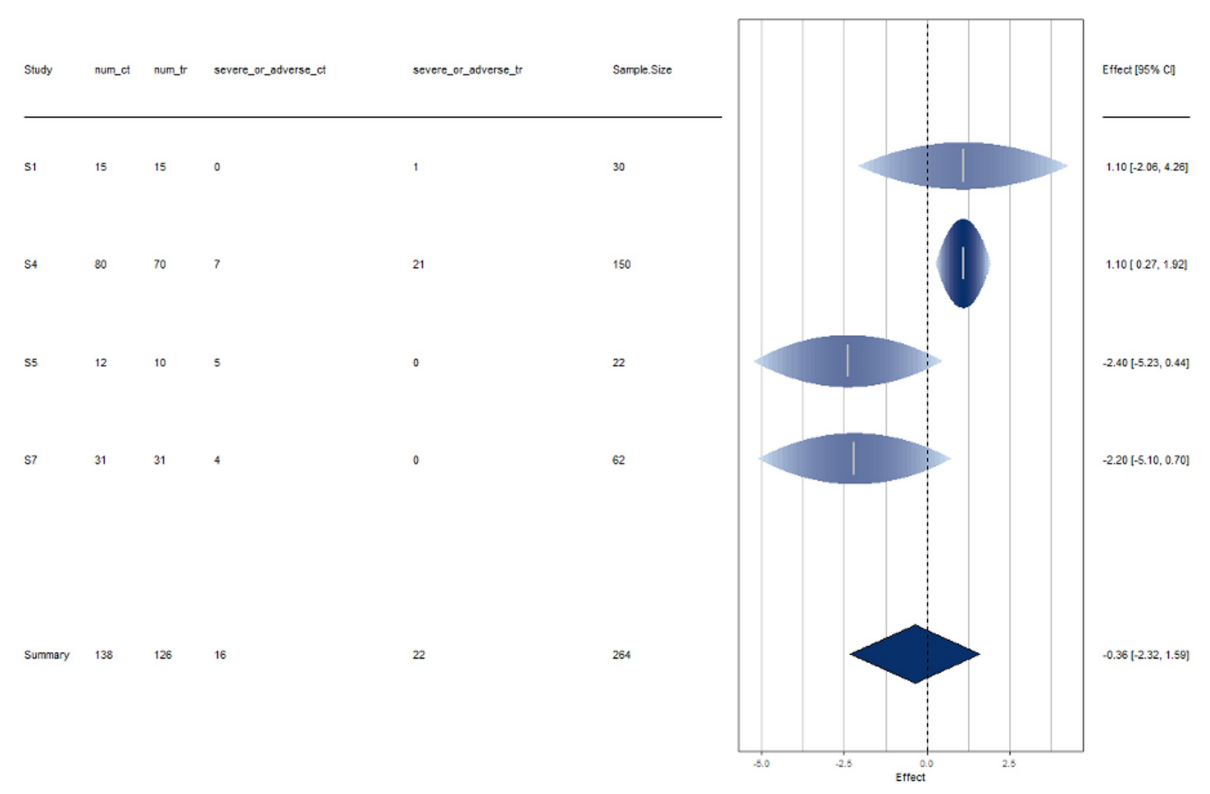

FIGURE 6: Disease severity forest plot

Interpretation

The results of all studies agree with the disease severity rate of HCQ treated COVID positive patients. There is slight disagreement shown by Study 4 by a moderate amount. 


\section{Cureus}

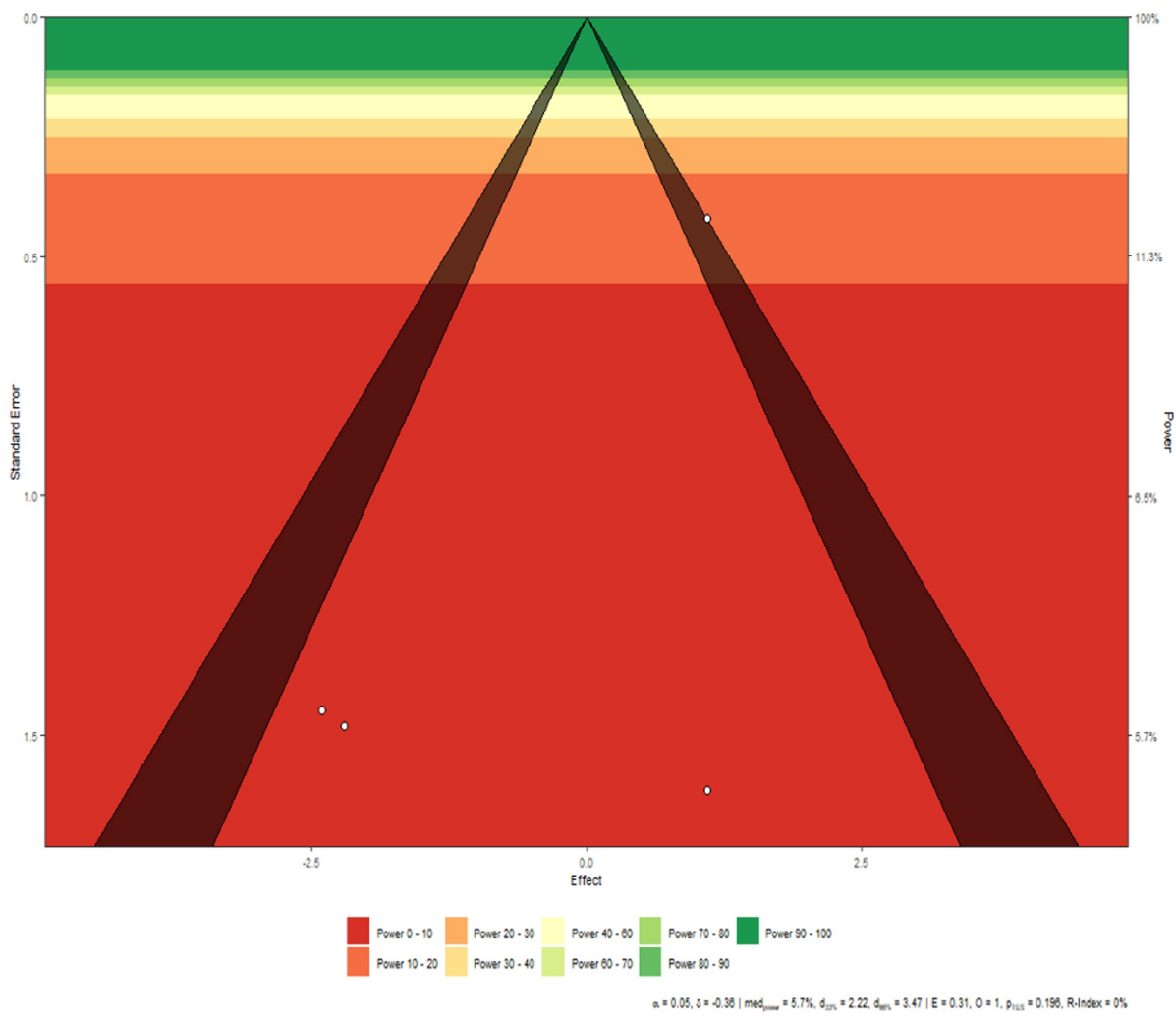

\section{FIGURE 7: Disease severity funnel plot}

Interpretation

The studies are symmetric except for Study 1, which falls on the border of the triangle. The remaining three studies, however, show symmetry among them.

A summary of the meta-analyses' findings is provided in Table 10 . 


\section{Cureus}

\begin{tabular}{|c|c|c|c|c|c|}
\hline $\begin{array}{l}\text { Meta- } \\
\text { analysis on }\end{array}$ & $\begin{array}{l}\# \\
\text { Studies } \\
\text { used }\end{array}$ & Random effect model conclusion & $\begin{array}{l}\text { Heterogeneity } \\
\text { between } \\
\text { studies }\end{array}$ & $\begin{array}{l}\text { Conclusion } \\
\text { from the } \\
\text { forest plot }\end{array}$ & Conclusion from the funnel plot \\
\hline $\begin{array}{l}\text { Progression/ } \\
\text { Improvement } \\
\text { Rate }\end{array}$ & 4 & $\begin{array}{l}\text { Progression rate in HCQ treated } \\
\text { individuals is on average } 1.2 \text { times } \\
\text { than non-HCQ individuals. This } \\
\text { implies HCQ patients are slightly at } \\
\text { an advantage on progression rate as } \\
\text { compared to non-HCQ patients. }\end{array}$ & $\begin{array}{l}\text { A bit of } \\
\text { heterogeneity } \\
\text { is observed } \\
\text { among } \\
\text { studies, which } \\
\text { might be } \\
\text { attributed to } \\
\text { Study } 6 \text {. }\end{array}$ & $\begin{array}{l}\text { All studies are } \\
\text { in agreement } \\
\text { except Study } \\
6 \text {, which shows } \\
\text { some } \\
\text { uncertainty in } \\
\text { its results. }\end{array}$ & $\begin{array}{l}\text { Study } 6 \text { has a bit of asymmetry, } \\
\text { implying a small publication } \\
\text { bias. It should be noted that } \\
\text { study } 6 \text { has very low power also } \\
\text { to distinguish the effect of HCQ } \\
\text { from non-HCQ treatment. }\end{array}$ \\
\hline $\begin{array}{l}\text { Severity } \\
\text { Rate }\end{array}$ & 4 & $\begin{array}{l}\text { individuals is on average } 0.69 \text { times } \\
\text { the non } \mathrm{HCQ} \text { individuals. This means } \\
\mathrm{HCQ} \text { treated patients are } 0.69 \text { times } \\
\text { more likely to face severe situations } \\
\text { than non-HCQ patients. }\end{array}$ & $\begin{array}{l}\text { Slight } \\
\text { heterogeneity } \\
\text { observed } \\
\text { among studies }\end{array}$ & $\begin{array}{l}\text { All studies are } \\
\text { in agreement } \\
\text { with respect to } \\
\text { the conclusion. }\end{array}$ & $\begin{array}{l}\text { Studies are symmetric except } \\
\text { Study } 1 \text {, showing slight } \\
\text { asymmetry ie publication bias. }\end{array}$ \\
\hline $\begin{array}{l}\text { Mortality } \\
\text { Rate }\end{array}$ & 2 & $\begin{array}{l}\text { The risk of mortality in } \mathrm{HCQ} \text { treated } \\
\text { individuals is on average } 2.54 \text { times } \\
\text { more than the non } \mathrm{HCQ} \text { individuals. }\end{array}$ & $\begin{array}{l}\text { No } \\
\text { heterogeneity } \\
\text { found, i.e., } \\
\text { studies are } \\
\text { homogeneous }\end{array}$ & $\begin{array}{l}\text { Study } 2 \text { is } \\
\text { more confident } \\
\text { about its } \\
\text { results and } \\
\text { Study } 1 \text { is } \\
\text { relatively less } \\
\text { confident. }\end{array}$ & $\begin{array}{l}\text { Slight asymmetry is noticed, } \\
\text { however, as the number of } \\
\text { studies are only two, it can be } \\
\text { due to random effects. }\end{array}$ \\
\hline
\end{tabular}

TABLE 10: Summary table

\section{Discussion}

The side effects of 4-Aminoquinolones are known to be dose-dependent increased risks for retinopathy, methemoglobinemia, and gastrointestinal (GI), renal, and cardiac toxicity [26]. HCQ co-administered with medications such as AZT further increases the risk of toxicity, particularly prolongation of the QT interval on electrocardiogram. The Borba et al. study revealed that males aged 50 with severe COVID symptoms and heart disease are at high risk for developing HCQ-related cardiac complications such as QT prolongation at higher doses of HCQ [21]. This toxicity is especially noted when combined with AZT, which is known to prolong the QT interval in populations with cardiac disease [21]. The studies by Tang et al. [24] and Chen J et al. [20] showed greater HCQ-related GI side effects as well.

In a post-marketing study by the Food and Drug Administration (FDA), it was also shown that the use of 4Aminoquinolones increased rates of cardiac arrhythmias, ventricular tachycardia, fibrillation, and torsades de pointes. Their analysis also noted adverse cardiac events in combination with the use of other QTprolonging medications such as azithromycin [27]. As a result, the FDA has cautioned the use of HCQ in COVID-19 patients, especially outside of the inpatient hospital setting [27]. Similarly, this meta-analysis supports that $\mathrm{HCQ}$ treated patients are more likely to have adverse side effects. It also appears that treatment with HCQ has a fatality rate of approximately 2.5 higher than with the control group.

The non-randomized study performed by Gautret et al. in the South of France included a total of 36 young patients with positive PCR test results and milder COVID-19 disease with no advanced comorbid medical conditions. A 50\% reduction in viral load was noted at one week with a low dose of HCQ with AZT [17]. This study was not powered to detect mortality outcomes. Similarly, Yang et al. [19], Mingxing et al. [23], and Chen J et al. [20] studied females with a median age of 45 and mild COVID-19 related upper respiratory/pneumonia symptoms, without co-existing co-morbid medical disease. Patients were stated to have improved time to clinical resolution in the HCQ treatment arm [20,22-23]. These results seem to be in line with the meta-analysis' of a slight disease improvement in COVID-19 patients treated with HCO as compared with the controls.

Furthermore, recent studies show a gender disparity, in that females show better outcomes as compared to similar male cohorts [14]. This gender disparity is seen in a recent study that noted that male patients with advanced age or multiple comorbid medical conditions are at higher risk for mortality $[11,14]$. The studies in this meta-analysis did not include these high-risk patients with underlying complex co-morbid medical conditions, severe cases of COVID-19, ARDS, or critical care patient populations. 


\section{Limitations}

Of note, the studies included in this meta-analysis have various definitions of control groups, which might affect the conclusion. However, with respect to the disease progression and severity meta-analysis, it appears that most of the studies are in agreement with the results, with slight exceptions, which might be attributed to chance. To get a more robust conclusion, the meta-analysis can be performed on more studies rather than six prospective control trials. Currently, there are $107 \mathrm{HCQ}$ clinical trials in the active recruitment phase [28]; as the pandemic continues to unfold, these future large multicenter randomized controlled clinical trials may be included in the meta-analysis to conclude the size effect of HCQ on COVID19.

\section{Conclusions}

Our study looks at three disease outcome measures of treatment with HCQ in patients with COVID-19: mortality rates, progression rates, and severity rates. In terms of mortality rates, it appears treatment with HCQ has a fatality rate that is 2.5 times greater than that of the control group. Similarly, HCQ treated patients are more likely to have an adverse clinical outcome and side effects. Lastly, there was a 1.2-times higher rate of clinical improvement in the group of HCQ treated patients, with mild to moderate symptoms as compared to the control group.

\section{Additional Information \\ Disclosures}

Human subjects: All authors have confirmed that this study did not involve human participants or tissue. Animal subjects: All authors have confirmed that this study did not involve animal subjects or tissue. Conflicts of interest: In compliance with the ICMJE uniform disclosure form, all authors declare the following: Payment/services info: All authors have declared that no financial support was received from any organization for the submitted work. Financial relationships: All authors have declared that they have no financial relationships at present or within the previous three years with any organizations that might have an interest in the submitted work. Other relationships: All authors have declared that there are no other relationships or activities that could appear to have influenced the submitted work.

\section{References}

1. Ahmad T, Haroon H, Baig M, Hui J: Coronavirus disease 2019 (COVID-19) pandemic and economic impact . Pak J Med Sci. 2020, 36:S4. 10.12669/pjms.36.covid19-s4.2638

2. Moher D, Liberati A, Tetzlaff J, Altman DG, the PRISMA Group: Preferred Reporting Items for Systematic Reviews and Meta-Analyses: the PRISMA statement. PLoS Med. 2009, 6:e1000097. 10.1371/journal.pmed.1000097

3. Li Q, Guan X, Wu P, et al.: Early transmission dynamics in Wuhan, China, of novel coronavirus-infected pneumonia. N Engl J Med. 2020, 382:1199-1207. 10.1056/nejmoa2001316

4. Coronavirus: DOD response timeline. U.S. Department of Defense . (2020). Accessed: July 27, 2020: https://www.defense.gov/Explore/Spotlight/Coronavirus/DOD-Response-Timeline/.

5. WHO announces COVID-19 outbreak a pandemic . (2020). Accessed: July 27, 2020: https://www.euro.who.int/en/health-topics/health-emergencies/coronavirus-covid19/news/news/2020/3/who-announces-covi....

6. Coronavirus timeline: tracking the critical moments of COVID-19 . (2020). Accessed: July 27, 2020: https://www.nbcnews.com/health/health-news/coronavirus-timeline-tracking-critical-moments-covid-19n1154341.

7. Stokes EK, Zambrano LD, Anderson KN, et al.: Coronavirus disease 2019 case Surveillance - United States, January 22-May 30, 2020. MMWR Morb Mortal Wkly Rep. 2020, 69:759-765. 10.15585/mmwr.mm6924e2

8. Yao X, Ye F, Zhang M, et al.: In vitro antiviral activity and projection of optimized dosing design of hydroxychloroquine for the treatment of severe acute respiratory syndrome coronavirus 2 (SARS-CoV-2). Clin Infect Dis. 2020, 71:732-739. 10.1093/cid/ciaa237

9. Rothan HA, Byrareddy SN: The epidemiology and pathogenesis of coronavirus disease (COVID-19) outbreak . J Autoimmun. 2020, 109:102433. 10.1016/j.jaut.2020.102433

10. Nile SH, Nile A, Qiu J, Li L, Jia X, Kai G: COVID-19: pathogenesis, cytokine storm and therapeutic potential of interferons. Cytokine Growth Factor Rev. 2020, 53:66-70. 10.1016/j.cytogfr.2020.05.002

11. Gupta A, Madhavan MV, Sehgal K, et al.: Extrapulmonary manifestations of COVID-19. Nat Med. 2020, 26:1017-1032. 10.1038/s41591-020-0968-3

12. Jin Y, Yang H, Ji W, Wu W, Chen S, Zhang W, Duan G: Virology, epidemiology, pathogenesis, and control of COVID-19. Viruses. 2020, 12:372. 10.3390/v12040372

13. Mason RJ: Pathogenesis of COVID-19 from a cell biology perspective . Eur Respir J. 2020, 55:2000607. 10.1183/13993003.00607-2020

14. Chakravarty D, Nair SS, Hammouda N, et al.: Sex differences in SARS-CoV-2 infection rates and the potential link to prostate cancer. Commun Biol. 2020, 3:374. 10.1038/s42003-020-1088-9

15. Schrezenmeier E, Dörner T: Mechanisms of action of hydroxychloroquine and chloroquine: implications for rheumatology. Nat Rev Rheumatol. 2020, 16:155-166. 10.1038/s41584-020-0372-x

16. Keyaerts E, Vijgen L, Maes P, Neyts J, Ranst MV: In vitro inhibition of severe acute respiratory syndrome coronavirus by chloroquine. Biochem Biophys Res Commun. 2004, 323:264-268. 10.1016/j.bbrc.2004.08.085

17. Gautret P, Lagier J-C, Parola P, et al.: Hydroxychloroquine and azithromycin as a treatment of COVID- 19: results of an open-label non-randomized clinical trial. Int J Antimicrob Agents. 2020, 56:105949. 


\section{Cureus}

10.1016/j.ijantimicag.2020.105949

18. FDA. Current and resolved drug shortages and discontinuations reported to FDA. (2020). Accessed: July 27, 2020: https://www.accessdata.fda.gov/scripts/drugshortages/dsp_ActiveIngredientDetails.cfm.

19. Yang H, Zhang J, Yu B, Zhao W: Statistical Methods for Immunogenicity Assessment. Taylor \& Francis Group, Oxfordshire, United Kingdom; 2015. 10.1201/b18761

20. Chen J, Liu D, Liu L, et al.: A pilot study of hydroxychloroquine in treatment of patients with common coronavirus disease-19 (COVID-19). J Zhejiang Univ (Med Sci). 2020, 49:215-219.

21. Borba MGS, Val FFA, Sampaio VS, et al.: Effect of high vs low doses of chloroquine diphosphate as adjunctive therapy for patients hospitalized with severe acute respiratory syndrome coronavirus 2 (SARSCoV-2) infection. A randomized clinical trial. JAMA Netw Open. 2020, 3:e208857.

10.1001/jamanetworkopen.2020.8857

22. Chen Z, Hu J, Zhang Z, et al.: Efficacy of hydroxychloroquine in patients with COVID- 19: results of a randomized clinical trial [Preprint]. Medrxiv. 2020, [Epub ahead of print]: 10.1101/2020.03.22.20040758

23. Huang M, Tang T, Pang P, et al.: Treating COVID-19 with chloroquine. J Mol Cell Biol. 2020, 12:322-325. 10.1093/jmcb/mjaa014

24. Tang W, Cao Z, Han M, et al.: Hydroxychloroquine in patients mainly with mild to moderate COVID- 19: an open-label, randomized, controlled trial. Medrxiv. 2020, 10.1101/2020.04.10.20060558

25. Levantovsky R, Vabret N: Hydroxychloroquine: small effects in mild disease . Nat Rev Immunol. 2020, 20:350-350. 10.1038/s41577-020-0315-4

26. Plaquenil ${ }^{\circledR}$. Hydroxychloroquine sulfate, USP. (2006). Accessed: July 27, 2020: https://www.accessdata.fda.gov/drugsatfda_docs/label/2007/009768s041lbl.pdf.

27. Department of Health and Human Services. Public Health Service. Food and Drug Administration. Center for Drug Evaluation and Research Office of Surveillance and Epidemiology. Pharmacovigilance memorandum. (2020). Accessed: July 27, 2020:

https://www.accessdata.fda.gov/drugsatfda docs/nda/2020/OSE\%20Review HydroxychloroquineCholorquine\%20-\%2019May2020_R....

28. ClinicalTrials.gov. Search of: hydroxychloroquine. Recruiting studies: covid - list results . (2020). Accessed: July 27, 2020: https://clinicaltrials.gov/ct2/results. 